\title{
Electromyography in Disorders of Muscle Tone
}

\author{
Andrew Eisen
}

\begin{abstract}
No single clinical electrophysiological test can evaluate disorders of muscle tone. These disorders, symptomatic of a variety of diseases have a multifactorial physiological basis. The several tests used are complimentary each aiming to study different aspects of spinal and supraspinal reflexes which become deranged. The $\mathrm{H}$ reflex and $\mathrm{F}$ wave ( $\mathrm{H}$ max/M max and $\mathrm{F} \max / \mathrm{M}$ max ratios) measure motoneuron pool excitability in general. The tendon reflex includes spindle mechanisms bypassed by the $\mathrm{H}$ reflex and, with limitations, comparison of $\mathrm{H} \max / \mathrm{M}$ max and $\mathrm{T} \max / \mathrm{M}$ max yields information about the $\gamma$ system. Tonic vibration of a tendon inhibits the $\mathrm{H}$ reflex from the same muscle. The TVR measures autogenous presynaptic inhibition exerted by the Ia afferents of the muscle. Recurrent inhibition via Renshaw cells is evaluated by studying the effect of collision on the $\mathrm{H}$ reflex. Reciprocal inhibition of the Ia afferents can be assessed by measuring $\mathrm{H}$ reflex change induced by stimulating Ia afferents from antagonists. Changes in the $\mathrm{H}$ reflex recovery cycle measure polysynaptic influences on spinal motoneuron excitability. Cutaneomuscular (flexor) reflexes measure poly- and oligosynaptic excitatory drive to spinal motoneurons and the blink reflex evaluates the excitatory drive to brainstem motoneurons. Long loop (segmental) responses can be evaluated by limb pertubation using a torque motor or electrical stimulation applied during voluntary muscle contraction. Finally needle electromyography is a more relevant test in several disorders of muscle tone such as the stiff-man syndrome and Isaacs' syndrome.
\end{abstract}

RÉSUMÉ: L'électromyographie dans les perturbations du tonus musculaire. Les perturbations du tonus musculaire ne peuvent être évaluées au moyen d'une épreuve électrophysiologique clinique unique. Ces perturbations, symptomatiques de différentes maladies, ont une base physiologique multifactorielle. Les multiples tests utilisés sont complémentaires, chaque test évaluant différents aspects des réflexes spinaux et supraspinaux qui peuvent être perturbés. Le réflexe $\mathrm{H}$ et l'onde $\mathrm{F}$ (les rapports $\mathrm{H} \max / \mathrm{M} \max$ et $\mathrm{F} \max / \mathrm{M} \max$ ) mesurent l'excitabilité du pool de motoneurones en général. Le réflexe ostéotendineux inclut des mécanismes en fuseau contournés par le réflexe $\mathrm{H}$ et, dans une certaine mesure, la comparaison de $\mathrm{H} \max / \mathrm{M} \max$ et de $\mathrm{T} \max / \mathrm{M} \max$ fournit de l'information sur le système. Les vibrations toniques d'un tendon inhibent le réflexe $\mathrm{H}$ du même muscle. Le RTV mesure l'inhibition présynaptique autogène exercée par les afférents Ia de ce muscle. L'inhibition récurrente via les cellules de Renshaw est mesurée par l'étude de l'effet de collision sur le réflexe $\mathrm{H}$. L'inhibition réciproque des afférents la peut être évaluée en mesurant le changement du réflexe $\mathrm{H}$ induit par la stimulation des afférents la qui proviennent des antagonistes. Les changements du cycle de récupération du réflexe $\mathrm{H}$ mesurent les influences polysynaptiques sur l'excitabilité du motoneurone spinal. Les réflexes cutanéomusculaires (flexion) mesurent la transmission excitative poly-et oligo-synaptique vers les motoneurones spinaux et le réflexe de clignotement évalue la transmission excitative vers les motoneurones du tronc cérébral. Les réponses des boucles longues (segmentaires) peuvent être mesurées par la perturbation d'un membre au moyen d'un moteur qui imprime un moment de torsion ou de stimulation électrique pendant la contraction musculaire volontaire. Finalement, l'électromographie à l'aiguille est le test le plus approprié dans plusieurs perturbations du tonus musculaire telles le syndrome de l'homme raide et le syndrome d'Isaac.

Can, J. Neurol. Sci. 1987; 14:501-505

Altered muscle tone is symptomatic of a variety of syndromes manifested, for example by spasticity, rigidity, abnormal posturing (dystonia) and hypotonia. These are usually identifiable without difficulty but are not readily defined in physiological terms. ${ }^{1-5}$ The physiological mechanisms underlying abnormal tone are complex and multifactorial. One or more of the following are involved in many syndromes characterized by altered tone: peripheral sensory receptors, primary afferent fibers and their presynaptic terminals, excitatory and inhibitory interneurons, alpha motorneurons and gamma (fusimotor) motorneurons. The commonly held view that disorders of muscle tone are due primarily to defective fusimotor control of muscle spindle endings is probably naive. ${ }^{6}$ Nevertheless, common to many of these disorders are altered supraspinal influences. As a result, changes in spinal cord function and segmental reflexes are reflected clinically by paresis or loss of dexterity.

Over the last 2 decades numerous electrophysiological methods have been developed for assessing altered muscle tone. Many complement each other, evaluating different aspects of neuronal circuitry, and it is unlikely that a single technique will 
evolve which will be applicable to all situations. In evaluating altered muscle tone, clinical electrophysiology attempts to answer at least three questions: ${ }^{7}$ 1) Is tone abnormal and if so to what extent?2) What physiological factor(s) underly the abnormality? 3) Is a particular therapeutic regimen efficacious and what is its mode of action?

This paper overviews many of the presently available electrophysiological tests used clinically to assess altered muscle tone (Table 1). It does not consider how these tests can be used to evaluate myorelaxant agents, (but see references $1,4,8$ ). Other contributors to this symposium will concentrate on specific aspects of clinical electrophysiology in altered muscle tone.

\section{The H Max/M Max Ratio}

This measures alpha motoneuron excitability reflecting the percentage of motorneurons activated via the monosynaptic reflex. ${ }^{9}$ It assumes that presynaptic inhibition, acting upon the terminal arborizations of the la afferents, remains constant. ${ }^{10}$ Long duration (1 ms) shocks, preferentially exciting la afferents, are commonly applied to the sciatic nerve in the popliteal fossa. The $\mathrm{H}$ reflex, with the maximum amplitude, is recorded from the soleus muscle (H Max). The same stimulation site is used to evoke a maximal motor compound action potential employing a supramaximal shock of $1 \mathrm{~ms}$ duration. The response is recorded over the soleus muscle (M Max). The normal range of $\mathrm{H} \mathrm{Max} / \mathrm{M}$ Max is 5-35\%. Although, the soleus $\mathrm{H}$ reflex is most commonly employed, monosynaptic responses with the same properties as the soleus $\mathrm{H}$ reflex can be elicited from many other muscles. They become more easily elicited in upper motor neuron lesions. "

The $\mathrm{H} \mathrm{Max} / \mathrm{M}$ Max ratio is increased in spasticity. ${ }^{9,12}$ In parkinsonian rigidity it is normal or reduced..$^{9,13.14}$

\section{The T Max/M Max Ratio}

This additionally measures excitability of the muscle spin-

Table 1: Electrophysiological tests used in assessment of muscle tone

\begin{tabular}{ll}
\hline \hline Test & Evaluate/Measures \\
\hline H Max/M Max Ratio & Alpha Motoneuron Excitability \\
T Max/M Max Ratio & Alpha Motoneuron Excitability \\
& Incorporates Spindle Mechanism \\
Tonic Vibration of Muscle & $\begin{array}{l}\text { Presynaptic Inhibition of } \\
\text { Monosynaptic Reflex }\end{array}$ \\
H Reflex Recovery Cycle & Polysynaptic Changes in Motor \\
& Neuron Excitability \\
Modification of H Reflex by & Recurrent Renshaw Inhibition
\end{tabular}

Maximal Conditioning Shock

Modification of $\mathrm{H}$ Reflex by

Simultaneous Sensory Stimulation

F Wave Responses

F Max, F/M Ratio

Limb Perturbation During

Intended Motor Acts

Nerve Stimulation During

Muscle Contraction

Blink Reflex

Cutaneomuscular

Flexor Reflexes

Needle Electromyography dles and the rheological properties of the stretched muscle bypassed by the $\mathrm{H}$ reflex. ${ }^{15}$ The ankle jerk is elicited by a single tap applied to the achilles tendon using an electromechanical hammer. The direction and percussive force of the hammer is varied to obtain a maximal amplitude response recorded over the gastrocnemius-soleus complex (T Max). This site is also used to record the maximal $\mathrm{M}$ wave elicited by supramaximal stimulation to the sciatic nerve at the popliteal fossa (M Max). In parkinsonian patients with rigidity the ratio is within the normal range (5-40\%). It is increased in spasticity.

\section{Vibratory Inhibition of the H Reflex (Tonic Vibration Reflex)}

In normal subjects, vibration applied to a limb muscle produces an illusion of movement, a slowly augmenting contraction (the tonic vibration reflex) and relatively non-specific inhibition of the monosynaptic reflex. ${ }^{16}$ This last effect predominantly results from autogenic presynaptic inhibition of the muscle Ia afferents responsible for the monosynaptic reflex. ${ }^{17-20}$

A $100 \mathrm{~Hz}$ vibrator is attached to the achilles tendon and the maximum amplitude $\mathrm{H}$ reflex is measured under control conditions and during vibration. Inhibition is expressed as [H Max during vibration/control $\mathrm{H}$ Max $\times 100$ ]. In normal (young) subjects there is about a $40 \%$ inhibition of $\mathrm{H}$ Max in the relaxed muscle. Presynaptic inhibition declines in older subjects and inhibition is reduced during muscle contraction in normal subjects. ${ }^{10}$

In spasticity, inhibition is significantly reduced and may be absent. ${ }^{10,20,21}$ This is also true during contraction, a modification of the technique that ensures that the inhibition being measured is truly presynaptic. ${ }^{10}$ Presynaptic inhibition is not reduced in parkinsonism ${ }^{12}$ and returns to normal within a year of complete spinal lesion. ${ }^{16}$

\section{H Reflex Recovery Cycle}

This monitors polysynaptic changes in motoneuron excitability secondary to segmental and suprasegmental mechanisms. ${ }^{18.22}$ Paired stimuli of equal strength, each of sufficient intensity to elicit a maximum $\mathrm{H}$ reflex, are applied at various interstimulus intervals. Results are expressed as a (percentage) ratio of the second (test) response, $\mathrm{H} 2$, to the first (conditioning) response, H1. In certain individuals results are stable over many hours. ${ }^{23}$

The normal $\mathrm{H}$ reflex recovery cycle follows a characteristic pattern: complete inexcitability for $2 \mathrm{msec}$, reappearance of the reflex for about $10 \mathrm{msec}$, marked inhibition for about $100 \mathrm{msec}$, facilitation for about $200 \mathrm{msec}$ and moderate inhibition for several seconds. Several aspects of the recovery cycle are measureable: $T_{0}$, time of onset of recovery, $T_{1}$, time of peak facilitation, $T_{2}$, duration of facilitation, $T_{3}$, recovery time constant, $R_{0}$, amplitude at onset of recovery and $R_{1}$, degree of facilitation. ${ }^{24}$

In spastic subjects there is a trend toward increased time of peak facilitation, increased duration of facilitation and increased recovery time constant. However, only the degree of facilitation, which approximately doubles, differs significantly from normals. ${ }^{24}$ The parkinsonian recovery curve exhibits a longer and higher period of facilitation. ${ }^{25}$

\section{Recurrent Renshaw Inhibition}

Inhibition by Renshaw cells reduces the excitability of motoneurons and when less effective results in motoneuron hyperactivity. Renshaw inhibition can be assessed using a double collision technique. ${ }^{26,27}$ This prevents excitatory postsynaptic 
potentials, created by Ia conditioning volleys, negating recurrent inhibition in the tested motoneurons. ${ }^{26}$ In essence the $\mathrm{H}$ reflex amplitude is compared when elicited by a stimulus adjusted to produce a maximum $\mathrm{H}$ response (conditioning shock) with that obtained by collision of this volley with a shock adjusted for a maximum $M$ wave (test shock). Conditioning-test interval is about $10 \mathrm{msec}$, being varied according to the subjects height. ${ }^{26}$ The intensity of recurrent inhibition is normal in parkinsonian rigidity ${ }^{12}$ but increased in spasticity. ${ }^{26}$

\section{Reciprocal Inhibition of Ia Afferents}

Muscle Ia afferents normally exert a measurable inhibitory influence upon the motoneurons of antagonists. ${ }^{28}$ This peripheral Ia reciprocal inhibition is different from central, supraspinal inhibition, but both types converge onto the same spinal la inhibitory interneurones. ${ }^{29,30}$ In the upper limbs, peripheral inhibition, is assessed by comparing the $\mathrm{H}$ reflex recorded from relaxed forearm flexor muscles evoked by median (flexor) nerve stimulation at the elbow with the effect of applying a simultaneous, conditioning, low intensity, stimulation of the radial (extensor) nerve at the spiral groove. Lower limb inhibition is assessed by measuring the decline in the soleus $\mathrm{H}$ reflex amplitude induced by simultaneous, threshold stimulation of the peroneal nerve. Unlike the upper limb, inhibition in the lower limb is weak in normal subjects and usually requires voluntary dorsiflexion of the foot before it is seen. ${ }^{28}$

In parkinsonism inhibition of the soleus $\mathrm{H}$ reflex is obvious, even at rest, and is more marked with voluntary contraction than in normals. ${ }^{12,29,30}$

\section{The F Wave Response}

The $F$ wave reflects recurrent discharge of antidromically activated motoneurons. ${ }^{31.32}$ Its shortest latency is a useful measure of conduction through the proximal peripheral nervous system, ${ }^{32}$ but other characteristics such as $F$ wave persistence $^{33-35}$ and amplitude ${ }^{36,37}$ are of particular relevance for evaluating central disorders. For example, increased $F$ wave persistence ${ }^{34}$ and amplitude ${ }^{36-38}$ has been demonstrated in spasticity. These studies suggest the $F$ wave is a measure of central motoneuron excitability. ${ }^{31,39}$ In acute stroke the amplitude of the $F$ wave is decreased. ${ }^{39,40}$ Recently, an increased amplitude of the $F$ wave has also been described in parkinsonian rigidity. ${ }^{12,41}$ However, before concluding that the $F$ wave amplitude is increased it is essential to be sure that baseline muscle activity was absent or the same as on the other side.

\section{Long-Loop Responses to Limb Perturbations}

Long-loop responses are synchronized muscular contractions associated with phasic aspects of movement; acceleration and velocity. The term response rather than reflex is preferred since volitional movement is an essential element when eliciting them. ${ }^{5}$ They are recognized by their latencies, which are considerably longer than a spinal reflex, but shorter than a pure voluntary contraction in response to a command.

The subject is instructed to maintain a limb posture to oppose a sudden perturbation (push or pull) delivered via a torque motor. The raw EMG is amplified, averaged and rectified. The stretched muscle reacts with a short latency spinal reflex and medium-latency and long-latency responses followed by voluntary movement. The responses, named $\mathrm{M} 1, \mathrm{M} 2$ and $\mathrm{M} 3{ }^{42}$ elicited by wrist perturbation, have latencies of about $30 \mathrm{msec}$ (spinal reflex), $50 \mathrm{msec}$ (medium-latency) and $80 \mathrm{msec}$ (longlatency) respectively. $\mathrm{M} 3$ is inconsistent and $\mathrm{M} 2$ and $\mathrm{M} 3$ may not be distinguishable. Long-loop responses elicited by leg perturbation have appropriately longer latencies since the conduction pathway includes much of the spinal cord. ${ }^{43}$

Long-loop responses are unrecordable when a perturbation is applied distal to a spinal lesion indicating the conduction pathway is supraspinal. In hemiplegia $M 1$, the spinal reflex component, is usually enhanced. M2 may be normal, enhanced or absent in the affected arm and leg. In many hemiplegics, late activity is seen occurring at about $100 \mathrm{msec}$. This is not voluntary since it is seen in a paretic limb, and not clonus because its frequency would be too fast. ${ }^{44}$ The dorsal columns, medial lemniscus, sensorimotor cortex and capsular corticomotoneurone pathways are essential for long-loop responses which are attenuated or lost when these are involved selectively. ${ }^{5,43}$ In rigid parkinsonians, long-loop responses are enhanced, ${ }^{42,44}$ an enhancement that correlates positively with the degree of rigidity. ${ }^{45}$

\section{Short and Long Latency Responses Elicited by Electrical Stimuli}

Electrical stimulation of the median nerve at the wrist induces three potentials of increasing latency, recordable from the contracting thenar muscle. The one with the shortest latency is a direct motor response (M-wave). It is followed by two responses, named R1 and R2 by Eisen et al. ${ }^{46}$ Their latencies are about $28 \mathrm{msec}$ and $46 \mathrm{msec}$ respectively. $\mathrm{R} 1$ has many of the properties of an $\mathrm{H}$ reflex. ${ }^{47.48}$ Evidence derived from patient studies suggests that $\mathrm{R} 2$ is a long-loop response synapsing within the sensorimotor cortex. ${ }^{49.50}$ It is likely, but unconfirmed, that R2 is the same response as M2 evoked by perturbation of a limb. ${ }^{51,52}$ Short and long latency responses can also be elicited by electrical stimulation of a leg nerve. ${ }^{46,50} \mathrm{R} 2$ has a longer latency than that obtained with arm stimulation, the difference being in keeping with the time it takes to transit along the spinal cord.

\section{The Blink Reflex}

The blink reflex can be elicited by mechanical or electrical stimulation. An ipsilateral early latency response, R1, (less than $12.9 \mathrm{msec}$ ) and longer latency bilaterally recorded responses, R2, (less than $43.7 \mathrm{msec}$ ) are evoked by supraorbital nerve stimulation. ${ }^{53} \mathrm{R} 2$ is equivalent to the clinically visible glabellar reflex. Both normally habituate rapidly and failure to do so is characteristic, but not specific of early Parkinson's disease. ${ }^{54.55}$ In stroke, especially early on, both early and late components are often absent or reduced in amplitude on the involved side. ${ }^{56}$

\section{Cutaneous Polysynaptic Reflexes}

When an electrical stimulus, of intensity sufficient to produce a tactile sensation is applied to the sural nerve, a reflex response of short latency $(40-60 \mathrm{msec})$ is recordable from the biceps femoris muscle. A stronger, painful, stimulus elicits a longer latency response ( $85-120 \mathrm{msec})$. If the stimulus is increased further both early and late components are recordable from other flexor muscles of the lower limb, for example the tibialis anterior. ${ }^{14.57,58}$ Inhibitory and subliminal excitatory effects may preclude recording cutaneomuscular reflexes from an inactive muscle. This may be overcome by introducing a test activity such as a monosynaptic $(\mathrm{H})$ reflex or tonic voluntary EMG activity. ${ }^{59}$

In spasticity, stimuli that are threshold for the late response, recordable in normal subjects only from the biceps femoris, 
elicit widespread flexor reflexes. ${ }^{59}$ In parkinsonian patients with rigidity the short latency response is enhanced and may become more widespread. However, the longer latency response is lost. ${ }^{58}$

\section{Needle Electromyography}

Abnormal muscle tone, although most commonly due to upper motoneuron disease and associated spasticity or extrapyramidal disease associated with rigidity, may also be seen as a manifestation of a variety of conditions having characteristic findings on needle electromyography.

Neuromyotonia (Isaacs' syndrome), is a sporadic disease usually starting with muscle twitching in the legs. As the disease progresses intermittent and then permanent muscle stiffness develops. If untreated, the arms become involved and laryngeal stridor may develop. Tendon reflexes are depressed or absent ${ }^{60}$ Abnormalities are seen on nerve-muscle biopsy affecting predominantly the motor nerve terminal which is considered to be the site of the abnormality responsible for the syndrome. ${ }^{61}$ Electromyography shows sustained or repetitive firing of motor units (continuous muscle fiber activity). In addition there are characteristic very high frequency $(300 \mathrm{~Hz})$ spontaneous discharges. Decrement in successive potential amplitude produces a unique and pathognomonic sound on the speaker. Many patients respond to phenytoin and carbamazepine. ${ }^{62}$ Similar EMG findings are seen in the much rarer congenital Schwartz-Jampel syndrome. ${ }^{63}$

Stiff-man syndrome is another disease characterized by continuous firing of otherwise normal motor units. Clinically there is rigidity initially involving axial musculature and later spreading to the limb girdles. Voluntary movement is difficult or impossible. ${ }^{64,65}$

\section{REFERENCES}

1. Young RR, Delwaide PJ. Spasticity. N Eng J Med 1981 ; 304: 28-33.

2. Rothwell JC, Obeso JA, Day BL, et al. Pathophysiology of dystonias. In: Motor Control Mechanisms in Health and Disease. Desmedt JE, ed. Raven Press, New York, 1983; 851-863.

3. Burke D. Stretch reflex activity in the spastic patient. In: Kyoto Symposia (EEG Suppl No. 36). Burser PA, Cobb WA, Okuma T, eds. Elsevier, Amsterdam, 1982; 172-178.

4. Davidoff RA. Antispasticity drugs: Mechanisms of action. Ann Neurol 1985; 17: 107-116.

5. Brooks VB. The neural basis of motor control. Oxford University Press, New York and Oxford, 1986: 111-128.

6. Burke D. Critical examination of the case for or against fusimotor involvement in disorders of muscle tone. In: Motor Control Mechanisms in Health Disease. Desmedt JE, ed. Raven Press, New York, 1983; 133-150.

7. Struppler A. Some new aspects of spasticity as revealed by clinical neurophysiology. In: Clinical Neurophysiology in Spasticity: Contribution to Assessment and Pathophysiology. Delwaide PJ, Young RR, eds. Elsevier, Amsterdam, 1985.

8. Delwaide PJ. Electrophysiological analysis of the mode of action of muscle relaxants in spasticity. Ann Neurol 1985; 17: 90-95.

9. Angel RW, Hoffmann WW. The $\mathrm{H}$ reflex in normal, spastic and rigid subjects. Arch Neurol 1963; 8: 591-596.

10. Iles JF, Roberts RC. Presynaptic inhibition of monosynaptic reflexes in the lower limbs of subjects with upper motoneuron disease. $\mathrm{J}$ Neurol Neurosurg Psychiat 1986; 49: 937-944.

11. Delwaide PJ, Martinelli P, Crenna P. Clinical neurophysiological measurements of spinal reflex activity. In: Spasticity: Disordered Motor Control. Year Book Medical Publishers, Chicago, 1980; 345-371.

12. Delwaide PJ. Are there modifications in spinal cord functions of parkinsonian patients? In: Clinical Neurophysiology in parkin- sonism. Delwaide PJ, Agnoli A, eds. Elsevier, Amsterdam, 1985; 19-32.

13. Bathien $\mathbf{N}$, Rondot $\mathrm{P}$. Reciprocal continuous inhibition in rigidity of parkinsonism. J Neurol Neurosurg Psychiat 1977; 40: 20-24.

14. Bathien N, Rondot P. Assessment of motor functions in extrapyramidal disorders. In: Recent Achievements in Restorative Neurology. 1. Upper Motor Neuron Functions and Dysfunctions. Eccles J, Dimitrijevic, eds. Karger, Basel, 1985; 211-221.

15. Pierrot-Deseilligny E. Étude par le réflexe monosynaptique (reflex H) de certains méchanismes impliqués dans la régulation tonique posturale normale et pathologique. Thèse Faculté de Médecine de Paris, 1966.

16. Ashby $P$, Verrier $M$, Carleton $S$, et al. Vibratory inhibition of the monosynaptic reflex and presynaptic inhibition in man. $I n$ : Spasticity: Disordered Motor Control. Feldman RG, Young RR, Koella WP, eds. Year Book Medical Publishers, Chicago, 1980: 335-344.

17. Gilles D, Lance JW, Neilson PD, et al. Presynaptic inhibition of the monosynaptic reflex by vibration. J Physiol 1969; 205: 329-339.

18. Delwaide P. Étude expérimentale de l'hyperréflexie tendineuse en clinique neurologique. Brussels, Editions Arscia Bruxelles, 1971.

19. Burke D, Ashby P. Are spinal presynaptic inhibitory mechanisms suppressed in spasticity? J Neurol Sci 1972; 15: 32 1-326.

20. Ashby P, Verrier M. Neurophysiological changes following spinal cord lesions in man. Can J Neurol Sci 1975;2: 91-100.

21. Ashby P, Verrier M. Neurophysiological changes in hemiplegia: Possible explanation for the initial disparity between muscle tone and tendon reflexes. Neurology 1976; 26: 1145-1151.

22. Martinelli P, De Pasqua V, Delwaide PJ. Réflexes évoqués par la stimulation du nerf tibial postérieur versus reflexe tendineux chezl'homme. Rev Electroencéphalogr Neurophysiol Clin 1979; 9: 76-81.

23. Delwaide PJ, Schoenen J, Burton L. Central actions of neurotropic drugs assessed by reflex studies in man. In: Desmedt JE, ed. Motor Control Mechanisms in Health and Disease. New York, Raven, 1983; 977-996.

24. Sax DS, Johnson TL. Spinal reflex actjvity in man: Measurement in relation to spasticity. In: Spasticity: Disordered Motor Control. Feldman RG, Young RR, Koella WP, eds. Year Book Medical Publishers, Chicago, 1980; 301-313;

25. Sax DS, Johnson TL, Cooper IS. Reflex activity in extrapyramidal disorders. Adv Neurol 1976; 14: 285-296.

26. Pierrot-Deseilligny E, Katz R, Hultborn H. Functional organization of recurrent inhibition in man: Changes preceding and accompanying voluntary movements. In: Motor Control Mechanisms in Health and Disease. Desmedt JE, ed. Raven Press, New York, 1983; 443-457.

27. Katz R, Pierrot-Deseilligny E. Recurrent inhibition of alpha-motoneurons in patients with upper motor neuron lesions. Brain 1982; 105: 103-124.

28. Tanaka $R$. Reciprocal la inhibitory pathway in normal man and in patients with motor disorders. In: Motor Control Mechanisms in Health and Disease. Desmedt JE, ed. Raven Press, New York, $1983 ; 433-441$.

29. Day BL, Rothwell JC, Marsden CD. Transmission in the spinal reciprocal Ia inhibitory pathway preceding willed movements of the human wrist. Neurosc Lett 1983; 37: 245-250.

30. Day BL, Marsden CD, Obeso JA, et al. Reciprocal inhibition between the muscles of the human forearm. J Physiol 1984; 349: 519-534.

31. Fisher MA. Physiology and clinical use of the F response. AAEE Minimonograph No 13, Johnson Co., Rochester MN, 1980.

32. Kimura J. Electrodiagnosis in Disorders of Nerve and Muscle: Principals and Practice. Philadelphia, FA Davis, 1983: 353-377.

33. Yates SK, Brown WE. Characteristics of the $F$ response: Single motor unit study. J Neurol Neurosurg Psychiatry 1974;42: 161-170.

34. Schiller HH, Stalberg E. F responses studied with single fibre EMG in normal subjects and spastic patients. J Neurol Neurosurg Psychiatry 1978; 41: 45-53.

35. Eisen $\mathbf{A}$, Hoirch $\mathbf{M}$, White $\mathbf{J}$, et al. Sensory group la proximal of conduction velocity. Muscle \& Nerve 1984; 7: 636-641.

36. Eisen $A$, Odusote $K$. Amplitude of the $F$ wave: A potential means of documenting spasticity. Neurology 1979; 29: 1306-1309.

37. Potts FA, Shahani BT, Young RR. F response amplitude and its relationship to the motor unit. Neurology 1981;31: 66 . 
38. Peiglou-Harmoussi S, Fawcett PRW, Howel D, et al. F-responses in syringomyelia. J Neurol Sci 1986; 75: 293-304.

39. Fisher MA, Shanani BT, Young RR. Assessing segmental excitability after acute rostral lesions. 1. The $F$ response. Neurology 1978; 28: 1265-1271

40. Fisher MA. F response analysis of motor disorders of central origin. J Neurol Sci 1983; 62: 13-22.

41. Abbruzzese G, Vische M, Ratto $S$, et al. Assessment of motor neuron excitability in parkinsonian rigidity by $F$ wave. J Neurol 1985; 232: 246-249.

42. Lee RG, Tatton WG. Motor responses to sudden limb displacements in primates with specific CNS lesions and in human patients with motor system disorders. Can J Neurol Sci 1975; 2 : 285-293.

43. Marsden CD, Merton PA, Morton HB, et al. The effect of lesions of the central nervous system on long-latency stretch reflexes in the human thumb. In: Cerebral Motor Control in Man: Long Loop Mechanisms. Desmedt JE, ed. Karger, Basel, 1978; 334-341.

44. Lee RG, Murphy JT, Tatton WG. Long-latency myotatic reflexes in man: Mechanism, functional significance and changes in patients with Parkinson's disease or hemiplegia. In: Motor Control Mechanisms in Health and Disease. Desmedt JE, ed. Raven Press, New York, 1983; 489-508.

45. Mortimer JA, Webster DD. Relationships between quantitative measures of rigidity and tremor and electromyographic responses to load perturbations in unselected normal subjects and Parkinson patients. In: Cerebral Motor Control in Man; Long Loop Mechanisms. Desmedt JE, ed. Karger, Basel, 1978; 342-360.

46. Eisen A, Burton K, Larsen A, et al. A new indirect method for measuring spinal cord conduction velocity in man. Electroencephalog Clin Neurophysiol 1984; 59: 204-213.

47. Upton ARM, McComas AJ, Sica REP. Potentiation of "late" responses evoked in muscles during effort. J Neurol Neurosurg Psychiatry 1971; 34: 699-711.

48. Stanley EF. Reflexes evoked in human thenar muscles during voluntary activity and their conduction pathways. J Neurol Neurosurg Psychiatry 1978; 41: 1016-1023.

49. Jenner JR, Stephens JA. Cutaneous reflex responses and their central nervous pathway studied in man. J Physiol 1982; 333: 405-419.

50. Eisen $A$, Hoirch $M$, Fink $M$, et al. Noninvasive measurement of central sensory and motor conduction. Neurology 1985; 35: 503-509.
51. Conrad B, Aschoff JC. Effects of voluntary isometric and isotonic activity on late transcortical reflex components in normal subjects and hemiparetic patients. Electroenceph Clin Neurophysiol 1977; 42: 107-116.

52. Iles JF. Responses in human pretibial muscles to sudden stretch and electrical stimulation. Exp Brain Res 1977; 30: 451-470.

53. Kimura J. The blink reflex as a clinical test. In: Electrodiagnosis in Clinical Neurology, Aminoff MJ, ed. Churchill Livingstone, New York, 1986; 347-383.

54. Garland HG. Parkinsonism. Br Med J 1952; 1: 153-155.

55. Nappi G, Sandrini G, Arrigo A. Blink reflex habituation as a tool for clinical and pharmacological research in Parkinson's disease. In: Clinical Neurophysiology in Parkinsonism. Delwaide PJ, Agnoli A, eds. Elsevier, Amsterdam, 1985; 33-48.

56. Kimura J, Wilkinson JT, Damasio $\mathrm{H}$, et al. Blink reflex in patients with hemispheric cerebrovascular accident (CVA). J Neurol Sci 1985; 67: 15-28.

57. Shahani BT, Young RR. Human flexor reflexes. J Neurol Neurosurg Psychiat 1971; 34: 616-627.

58. Shahani, Young RR. The flexor reflex in spasticity. In: Spasticity: Disordered Motor Control. Feldman RG, Young RR, Koella WP, eds. Year Book Medical Publishers, Chicago, 1980; 287-300.

59. Meinck HM, Benecke R, Kuster S, et al. Cutaneomuscular (flexor) reflex organization in normal man and in patients with motor disorders. In: Motor Control Mechanisms in Health and Disease. Desmedt JE, ed. Raven Press, New York, 1983; 787-796.

60. Isaacs $\mathrm{H}$. Syndrome of continuous muscle fiber activity. J Neurol Neurosurg Psychiat 1961; 24: 319-325.

61. Warmolts JR, Mendell JR. Neuromyotonia: Impulse-induced repetitive discharges in motor nerves in peripheral neuorpathy. Ann Neurol 1980; 7: 245-250.

62. Isaacs $H$, Heffron JJA. The syndrome of "continuous muscle fiber activity" cured: Further studies. J Neurol Neurosurg Psychiat 1974; 37: 1231.

63. Jablecki C, Schultz P. Single fiber recordings in the SchwartzJampel syndrome. Muscle \& Nerve 1982; 5(S): 64-69.

64. Gordon EE, Janusko DM, Kaufman I. A critical survey of stiffman syndrome. Am J Med 1967; 42: 582-599.

65. Miller F, Korsvik MS. Baclofen in the treatment of stiff-man syndrome. Ann Neurol 1981; 9: 511-512. 